\title{
May Mutation of SNP rs1800947 Affects Length of Stay \\ Outcome of COVID-19 suspects? [version 1; peer review:
}

\section{awaiting peer review]}

\section{Zulmansyah Zulmansyah (D, Gaga Irawan Nugraha, Dwi Agustian, Dida Akhmad Gurnida}

Faculty of Medicine, Padjadjaran University, Indonesia, Sumedang, Indonesia

\author{
V1 First published: $14 \mathrm{Dec} 2021,10: 1278$ \\ https://doi.org/10.12688/f1000research.73568.1 \\ Latest published: 14 Dec 2021, 10:1278 \\ https://doi.org/10.12688/f1000research.73568.1
}

\begin{abstract}
Coronavirus disease 2019 (COVID-19) is a new type of respiratory infection that first emerged in December 2019 in Wuhan, Hubei, China. COVID-19 is caused by a new type of virus called severe acute respiratory syndrome coronavirus 2 (SARS-CoV-2). This study aims to determine the association of SNP CRP rs1800947 gene in suspected COVID-19 patients to length of stay at Al Ihsan Hospital, and Banten Hospital in June-November 2020. This study used data from 60 patients, all patients were suspect COVID-19. The subject was 29 COVID-19 people were confirmed, whereas 31 people were not. A statistics analysis due to pearson correlation and linear multi regretion. This study found a significant assosiation between the subject. The results of this study were the relationship between SNP rs1800947 and outcome, a fairly strong association level relationship was found in the SNP rs1800947 ( $p$-value= 0.045, association=0.537). The association between length of stay and CRP levels has a low level of association ( $p$-value $=0.015$, association $=0.378$ ). The SNP genotype rs1800947 $\mathrm{G}$ had a longer treatment duration of 0.14778 days compared to the SNPrs1800947 C genotype. CRP levels showed that higher CRP levels increased the length of treatment compared to normal CRP levels. Where high CRP levels are at risk of 0.6330 days longer than normal CRP while very high CRP is at risk of 2.9561 days longer than Normal CRP levels. In general, the gene SNP rs1800947 and CRP levels, together affect the outcome of patients with suspected COVID-19.
\end{abstract}

Keywords

COVID-19, CRP levels, SNP rs180094, length of stay

\section{Open Peer Review}

Approval Status AWAITING PEER REVIEW

Any reports and responses or comments on the article can be found at the end of the article. 


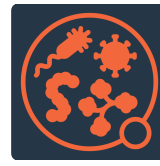

This article is included in the Pathogens

gateway.

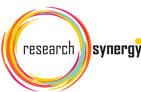

This article is included in the Research Synergy

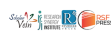

Foundation gateway.

Corresponding author: Zulmansyah Zulmansyah (zulluz812@gmail.com)

Author roles: Zulmansyah Z: Conceptualization, Data Curation, Formal Analysis, Funding Acquisition, Investigation, Methodology, Project Administration, Resources, Software, Validation, Visualization, Writing - Original Draft Preparation, Writing - Review \& Editing; Nugraha GI: Conceptualization, Data Curation, Methodology, Supervision, Validation, Visualization, Writing - Review \& Editing; Agustian D: Conceptualization, Data Curation, Methodology, Supervision, Validation, Visualization, Writing - Review \& Editing; Gurnida DA: Conceptualization, Data Curation, Methodology, Supervision, Validation, Visualization, Writing - Review \& Editing

Competing interests: No competing interests were disclosed.

Grant information: The author(s) declared that no grants were involved in supporting this work.

Copyright: (c) 2021 Zulmansyah Z et al. This is an open access article distributed under the terms of the Creative Commons Attribution License, which permits unrestricted use, distribution, and reproduction in any medium, provided the original work is properly cited.

How to cite this article: Zulmansyah Z, Nugraha GI, Agustian D and Gurnida DA. May Mutation of SNP rs1800947 Affects Length of Stay Outcome of COVID-19 suspects? [version 1; peer review: awaiting peer review] F1000Research 2021, 10:1278 https://doi.org/10.12688/f1000research.73568.1

First published: 14 Dec 2021, 10:1278 https://doi.org/10.12688/f1000research.73568.1 


\section{Introduction}

COVID-19 is a disease caused by severe acute respiratory syndrome coronavirus 2 (SARS-CoV-2). COVID-19 can cause respiratory system disorders, ranging from mild symptoms, such as flu-like symptoms, to lung infections, such as pneumonia. COVID-19 was declared a Public Health Emergency of International Concern (PHEIC) by the World Health Organization (WHO) on January 30, 2020, and its status was later renewed to pandemic. ${ }^{1}$ There were $120,417,285$ cases reported until March 15, 2021, with 1,419,455 cases reported in Indonesia, resulting in 38,426 deaths. ${ }^{2}$

Some factors have been known to result in worse outcome in inflammatory diseases, including C-reactive protein (CRP). $\mathrm{C}$-reactive protein (CRP) is an acute-phase protein, an early marker of inflammation or infection produced mainly in hepatocytes. CRP plays a role in inflammatory processes and the host immunological response to infection through complement pathways, apoptosis, phagocytosis, nitric oxide (NO) release, and production of cytokines. ${ }^{3} \mathrm{CRP}$ level has drawn interest in recent research as diagnostic tools and progression model of infections in lower respiratory tract, ${ }^{4}$ pneumonia, and severity of COVID-19.

Single nucleotide polymorphisms (SNP) in the CRP gene show an association with CRP variability. The National Center for Biotechnology Information (NCBI) SNP Database (http://www.ncbi.nlm.nih.gov/SNP) contains more than 30 SNPs of the human CRP gene (as of July 2021). ${ }^{6}$ The most researched CRP gene variant is rs 1800947 , which features a guanine to cytosine substitution at position 1059. Variations in this region have been known to be related with alteration of serum $\mathrm{CRP},{ }^{7}$ and it is known to be a prognosis of the risk of some chronic diseases. ${ }^{8}$

Until now, the relationship between the CRP level and SNP variability in COVID-19 patients has not been clearly highlighted. Despite this, the relationship between these factors and prognosis of the disease is urgently needed to immediately give the best intervention for patients admitted to hospital to decelerate progression of the disease. Moreover, these factors will also be useful to predict the outcome of suspected COVID-19 and confirmed positive cases. This study is aimed to scientifically evaluate the CRP level and SNP rs180094 variability towards prognosis of disease in COVID-19 patients in comparison with confirmed negative cases with similar symptoms admitted to the hospital.

\section{Methods}

Patients

Patients admitted to Al-Ihsan Central Hospital, and Banten Central Hospital, Banten, West Java, Indonesia during July to November 2020 with following symptoms of respiratory tract infection: 1) high fever $\left(\geq 38^{\circ} \mathrm{C}\right)$; 2) respiratory symptoms such as cough, runny nose, cold, shortness of breath, sore throat, or confirmed positive for pneumonia. There is no other cause based on a conclusive clinical picture. Further, patients also had to have: 1) history of traveling or staying in areas with reported transmission of COVID-19; or 2) contact with suspect and confirmed positive person. Patients were directly swabbed in nasopharynx at day of admission and samples were directly send to COVID-19 diagnostic laboratory for PCR test.

The study was conducted according to the guidelines of the Declaration of Helsinki, and approved by the Institutional Review Board (IRB) of our Institute (ethical approval code: 275/IJN6.KEP/EC/2020).

CRP levels

CRP levels were measured using enzyme-linked immunosorbent assay (ELISA) with samples from blood drawn during admission. CRP ELISA kit (Epithod ${ }^{\circledR} 616$ CRP Test Kit) was used for this purpose. CRP was classified into three categories based on Landry et al.. ${ }^{10}$ Normal: CRP level of 3-10 mg/L; high: CRP level of 10-100 mg/L; and very high: CRP level $>100 \mathrm{mg} / \mathrm{L}$

\section{SNP rs1800947 variations}

Blood samples were extracted using a magnetic bead-based method with a commercially available kit $\left(\right.$ MagMAX $^{\mathrm{TM}}$ Viral/Pathogen Nucleic Acid Isolation Kit, A42352). SNP rs1800947 were detected using polymerase chain reaction (PCR) method using PCR kit (MyTaq ${ }^{\mathrm{TM}}$ HS Red Mix, BIO-25048) according to manufacturer's protocol with following primers, forward: 5'-GATCTGTGTGTGATCTGAGAAACCTCT 3'; reverse: 5'-GAGGATCCAGAGACAGAGACG TG $3^{\prime}$. Later, the DNA was sequenced using Sanger sequencing for detection of SNP variations.

\section{Statistical analysis}

A statistical analysis by Pearson correlation and linear multi-regression was performed. Regression analysis is an analysis used to describe the relationship between an independent variable on dependent variable that can be declared as a form of mathematical model. 
Linear regression equation models in general:

$$
Y=\beta_{0}+\beta_{1} X_{1}+\ldots+\beta_{i} X_{i}
$$

In the category variable with a nominal/ordinal measurement scale to facilitate the analysis process requires conversion to numerical forms using dummy variables that take binary numbers 1 and 0 .

Suppose for the $\mathrm{X} 2$ variable CRP content with two normal, and high categories, two dummy variables are formed: $X_{2(1)}=1$ for high levels, 0 for others

\section{Results}

This study used data from 60 patients, all patients were suspect COVID-19. Patients were divided into two groups: 29 positive patients (COVID-19 (+)) and 31 unconfirmed patients (COVID-19 $(-)$ ). The mean age was 48 years in both groups. Male patients were more prevalent in COVID-19 (+) compared with the COVID-19 (-) group. The COVID-19 (+) group was found to have twice as many patients with comorbidities as the non-COVID group, however the results were not significant due to the small sample size. More patients with low nutritional status were found in the non-COVID group. The distribution of patients for each CRP level was balanced for each group. Genotype variation $(\mathrm{G}>\mathrm{C})$ was found in balance for each group (Table 1).

The results in Table 2 show how large the association between lengths of stay for CRP levels, SNPs rs 1800947. From the results of this study, the association between length of stay and CRP levels has a low level of association ( $\mathrm{p}$-value $=0.015$, association $=0.378$ ). A fairly strong association level relationship was found in SNP rs1800947 (p-value $=0.045$, association $=0.537$ ). This means that if the subject has a CG gene mutation, the length of stay will be longer. Results for confounding variables, very low association rates were found in the age group, and comorbid diabetes mellitus. Meanwhile, low association levels were found in gender, comorbid hypertension, and heart disease.

Regression analysis is an analysis used to explain the relationship between an independent variable on the dependent variable which can be expressed as a form of mathematical model. The results obtained from the regression analysis (Table 3) for the SNP genotype rs1800947 G, the length of treatment was 0.14778 days longer than the SNPrs 1800947 C genotype, and the CRP levels in general showed that the higher the CRP level, the longer the treatment compared to

Table 1. Subject demographic.

\begin{tabular}{|c|c|c|c|c|}
\hline \multirow[t]{2}{*}{ Variable } & \multicolumn{2}{|c|}{ Value or number of patients } & \multirow[t]{2}{*}{ Risk ratio } & \multirow[t]{2}{*}{ p-value } \\
\hline & $\begin{array}{l}\text { COVID-19 (+) } \\
(n=29)\end{array}$ & $\begin{array}{l}\text { CoVID-19 (-) } \\
(n=31)\end{array}$ & & \\
\hline $\begin{array}{l}\text { Age (year } \pm \text { st.dev) } \\
\text { [median (range)] }\end{array}$ & $48 \pm 10.3[47(26-64)]$ & $48.6 \pm 20.4[47.5(0-86)]$ & & 0.880 \\
\hline \multicolumn{5}{|l|}{ Gender } \\
\hline Male & $21(72.4 \%)$ & $15(48.4 \%)$ & $1.50[0.47-0.99]$ & 0.060 \\
\hline Female & $8(27.6 \%)$ & $16(51.6 \%)$ & REFERENCE & \\
\hline \multicolumn{5}{|l|}{ Comorbidity } \\
\hline Hypertension & $7(24.1 \%)$ & $4(12.9 \%)$ & $1.87[0.61-5.73]$ & 0.270 \\
\hline Heart disease & $3(10.3 \%)$ & $1(3.2 \%)$ & $0.80[0.20-3.28]$ & 0.760 \\
\hline Diabetes mellitus & $2(6.9 \%)$ & $1(3.2 \%)$ & $2.14[0.20-22.34]$ & 0.530 \\
\hline \multicolumn{5}{|l|}{ CRP level } \\
\hline Normal & $17(41.4 \%)$ & $17(54.8 \%)$ & REFERENCE & \\
\hline High & $12(58.6 \%)$ & $14(45.2 \%)$ & $0.92[0.51-1.64]$ & 0.770 \\
\hline \multicolumn{5}{|l|}{ Genotype } \\
\hline \multicolumn{5}{|l|}{ Rs1800947 } \\
\hline C & $22(75.9 \%)$ & $25(80.6 \%)$ & REFERENCE & \\
\hline G & $7(24.1 \%)$ & $6(19.4 \%)$ & $1.25[0.47-3.28]$ & 0.650 \\
\hline
\end{tabular}

*CRP levels: Normal: 3-10 mg/L, high: >10 mg/L. ${ }^{9}$ 
Table 2. Length of hospitalization in the COVID-19 subgroup.

\begin{tabular}{|c|c|c|c|c|c|}
\hline Dependent variable & Independent variable & COVID-19 (+) & COVID-19 (-) & Total & p-value \\
\hline \multirow[t]{6}{*}{ Length of stay } & CRP Level & 29 & 31 & 60 & 0.015 \\
\hline & Normal & 17 & 17 & & \\
\hline & High & 12 & 14 & & \\
\hline & SNP rs1800947 & 29 & 31 & 60 & 0.045 \\
\hline & CC & 22 & 25 & & \\
\hline & CG & 7 & 6 & & \\
\hline \multirow[t]{5}{*}{ Length of stay } & Confounding variable & & & & \\
\hline & Comorbidity & & & & \\
\hline & Hypertension & 7 & 4 & 11 & 0.012 \\
\hline & Heart disease & 3 & 1 & 4 & 0.032 \\
\hline & Diabetes mellitus & 2 & 1 & 3 & 0.038 \\
\hline
\end{tabular}

Length of stay: COVID-19 (+) : 15.12 days, COVID-19 (-): 17.25 days.

*CRP levels: Normal: 3-10 mg/L, high: >10 mg/L. ${ }^{9}$

Table 3. Length of stay association in COVID-19 subgroup.

\begin{tabular}{|l|l|l|l|l|}
\hline Dependent variable & Independent variables & $\mathbf{p}$-value & Association & Level association \\
\hline Length of stay & CRP level & 0.015 & 0.378 & Low \\
\hline SNP rs1800947 & 0.045 & 0.537 & Strong \\
\hline Length of stay & $\begin{array}{l}\text { Confounding variable } \\
\text { Age }\end{array}$ & 0.673 & 0.058 & Very low \\
\hline $\begin{array}{l}\text { Gender } \\
\text { Comorbidity }\end{array}$ & 0.104 & 0.322 & Low \\
\hline Hypertension & & & \\
\hline Heart disease & 0.012 & 0.207 & Low \\
\hline Diabetes mellitus & 0.032 & 0.230 & Low \\
\hline
\end{tabular}

*Length of stay: COVID-19 (+): 15.12 days; COVID-19 (-): 17.25 days.

Table 4. Length of stay regression results.

\begin{tabular}{|l|l|l|l|l|l|}
\hline Variable & Parameter symbol & Coefficient & Standard error & p-value & Significance \\
\hline Constant & $\beta_{0}$ & 5.6957 & 0.27447 & 0.0003 & $\checkmark$ \\
\hline SNP rs1800947 & $\beta_{1}$ & & & & \\
\hline CG & & 0.14778 & 0.0868 & 0.0041 & $\checkmark$ \\
\hline CRP Level & $\beta_{2}$ & & & & \\
\hline Normal & $(1)$ & 0.6330 & 0.0877 & $<0.00001$ & $\checkmark$ \\
\hline High & $(2)$ & 2.3231 & 0.1132 & $<0.00001$ & $\checkmark$ \\
\hline
\end{tabular}

${ }^{*}$ CRP levels: Normal: 3-10 mg/L; high: >10 mg/L. ${ }^{9}$

normal CRP levels. Where high CRP levels are at risk of 0.6330 days longer than normal CRP while very high CRP is at risk of 2.9561 days longer than normal CRP levels (Table 4).

\section{Discussion}

Several studies have confirmed that serum CRP levels are an important marker for clinical diagnosis and severity assessment in pneumonia, ${ }^{11}$ and one study found that rs 1800947 is closely linked to CRP expression. ${ }^{12}$ SNP rs 1800947 
only has two alleles, which shows substitutional mutations from one other nucleotide, at rs 1800947 only found alleles G and $\mathrm{C}$ in the population. ${ }^{13} \mathrm{CRP}$ plasma levels were shown to be lower in C-allele carriers than in GG homozygotes in previous studies. The rs 1800947 polymorphism's C-allele explained 6.2 per cent of the variation in CRP levels. ${ }^{14}$ An interesting point of this study was the number of C-allele carriers was very large, $24.1 \%$ for Covid-19 (+) and $19.4 \%$ for Covid-19 (-).

The majority of SNPs have no association to illness or functional problems. However, if SNPs are positioned on a gene or regulator area (promoter, enhancer, etc.), they can impact the function of genes involved in the disease mechanism. ${ }^{13}$ Another study found that the impact of the CRP gene polymorphism rs 1800947 may differ. Because the rs 1800947 polymorphism is silent, the mechanism underlying the expressed CRP levels could be the linkage disequilibrium of the rs 1800947 polymorphism with other functional variants both within and outside the CRP gene. Alternatively, it's possible that this polymorphism changes the kinetics of CRP translation, resulting in varying CRP levels throughout the body. ${ }^{12}$

Patients with COVID-19, increased CRP correlates with damage in the lungs, so CRP can be an important indicator to predict severity and mortality in patients with COVID-19 who are hospitalized. These results are in line with previous research conducted by Wang et al., ${ }^{15}$ showed that in the early stages of COVID-19 disease, CRP levels were positively correlated with pulmonary lesions. CRP levels can describe the severity of the disease and should be used as the main indicator for disease monitoring. Significant increase in CRP levels and erythrocyte sedimentation rate in the early stages of severe COVID-19 patients. CRP has also been associated with disease progression and has shown good performance in predicting severity in the early stages of COVID-19 disease. ${ }^{16}$

CRP is an acute-phase protein produced by the liver in response to increased levels of inflammatory cytokines, especially Intelleukin-6 (IL-6) and tumor necrosis factor $\alpha$ (TNF- $\alpha$ ). CRP levels are known to increase in response to tissue damage, infection and inflammation and their concentration will increase in the circulation during inflammatory events. CRP is not only a marker of inflammation but also plays an active role in the inflammatory process. ${ }^{17}$ Patients with COVID-19 show higher leukocyte counts and elevated levels of pro-inflammatory cytokines such as IL-6, IL-10, granulocyte colony stimulating factor (G-CSF), monocyte chemoattractant protein 1 (MCP1), macrophage inflammatory protein (MIP) $1 \alpha$, and TNF- $\alpha$. IL- 6 level is also related to the severity of the patient's condition, the more severe the patient's condition, the higher the level of IL-6 and this will stimulate the liver to produce CRP. ${ }^{17}$

Nonetheless, certain substantial limitations of this study should be mentioned, such as its small sample size, but we had enough power to detect significant differences between the differences we identified. Therefore, our results should eventually be confirmed. However, the findings suggest that CRP levels, and the SNP rs180094 also may play a role in disease prognosis. This research can be used as a reference for researchers who will research similar things as well as a reference for COVID-19 examinations in the future.

\section{Conclusions}

The association between length of stay and CRP levels has a low level of association ( $\mathrm{p}$-value $=0.015$, association $=$ 0.378). A fairly strong association level relationship was found in the SNP rs 1800947 ( -value $=0.045$, association $=$ 0.537). The SNP genotype rs $1800947 \mathrm{G}$ was 0.2677 days faster than the SNP genotype rs $1800947 \mathrm{C}$ in patients with confirmed COVID-19 (+). In general, CRP levels show that the higher the CRP levels, the longer the length of treatment compared to Normal CRP levels. Where high CRP levels are at risk of 1.3928 days longer than normal CRP while very high CRP is at risk of 4.1087 days longer than Normal CRP levels in confirmed COVID-19 (+) patients.

\section{Data availability}

Underlying data

Figshare: Underlying data for 'May mutation of SNP rs 1800947 affect length of stay outcome of COVID-19 suspects?'. https://doi.org/10.6084/m9.figshare.16863259.v1. ${ }^{18}$

Data are available under the terms of the Creative Commons Attribution 4.0 International license (CC-BY 4.0).

\section{Ethics and consent}

The study was conducted according to the guidelines of the Declaration of Helsinki, and approved by the Institutional Review Board (IRB) of our Institute (ethical approval code: 275/IJN6.KEP/EC/2020). Data was collected after the patient received informed consent. 


\section{Author contributions}

Zulmansyah, conceptualization, data curation, formal analysis, funding acquisition, investigation, methodology, project administration, resources, software, validation, visualization, writing-original draft, writing-review and editing.

Gaga Irawan Nugraha, conceptualization, data curation, methodology, supervision, validation, visualization, writingreview and editing.

Dwi Agustian, conceptualization, data curation, methodology, supervision, validation, visualization, writing-review and editing.

Dida Akhmad Gurnida, conceptualization, data curation, methodology, supervision, validation, visualization, writingreview and editing.

\section{Acknowledgments}

Thanks to the assistance of different parties, this study has been operating fine. As a result, we would like to express our gratitude to Al-Ihsan Central Hospital, Banten Central Hospital, and Parasitology Laboratory, Faculty of Medicine, Padjadjaran University, Indonesia.

1. Aviani JK, Halim D, Soeroto AY, et al.: Current views on the potentials of convalescent plasma therapy (CPT) as Coronavirus disease 2019 (COVID-19) treatment: A systematic review and meta-analysis based on recent studies and previous respiratory pandemics. Rev. Med. Virol. 2021; (January).

Publisher Full Text

2. Rodriguez-Morales AJ, Cardona-Ospina JA, Gutiérrez-Ocampo E, et al.: Clinical, laboratory and imaging features of COVID-19: A systematic review and meta-analysis. Travel Med. Infect. Dis. 2020; 34(March): 101623.

PubMed Abstract | Publisher Full Text | Free Full Text

3. Osman R, L'Allier PL, Elgharib N, et al.: Critical appraisal of C-reactive protein throughout the spectrum of cardiovascular disease. Vasc. Health Risk Manag. 2006; 2(3): 221-237. PubMed Abstract | Publisher Full Text | Free Full Text

4. Melbye $H$, Hvidsten $D$, Holm A, et al.: The course of C-reactive protein response in untreated upper respiratory tract infection. J. R. Coll. Gen. Pract. 2004; 54(506): 653-658. PubMed Abstract | Free Full Text

5. Sharifpour M, Rangaraju S, Liu M, et al.: C-Reactive protein as a prognostic indicator in hospitalized patients with COVID-19. PLOS One. 2020; 15(11 November): e0242400-e0242410. PubMed Abstract | Publisher Full Text | Free Full Text

6. Smigielski EM, Sirotkin K, Ward M, et al.: dbSNP: a database of single nucleotide polymorphisms. Nucleic Acids Res. $2000 \mathrm{Jan}$ 28 (1): 352-355

PubMed Abstract | Publisher Full Text | Free Full Text

7. Szalai AJ, Wu J, Lange EM, et al.: Single-nucleotide polymorphisms in the C-reactive protein (CRP) gene promoter that affect transcription factor binding, alter transcriptional activity, and associate with differences in baseline serum CRP level. J. Mol. Med. (Berl). 2005 Jun; 83(6): 440-447. PubMed Abstract | Publisher Full Text

8. Kuhlenbaeumer G, Huge A, Berger K, et al.: Genetic variants in the $C$-reactive protein gene are associated with microangiopathic ischemic stroke. Cerebrovascular diseases (Basel, Switzerland). 2010; 30(5): 476-482.

PubMed Abstract | Publisher Full Text
9. Sproston NR, Ashworth J]: Role of C-reactive protein at sites of inflammation and infection. Front. Immunol. 2018; 9(APR): 1-11. Publisher Full Text

10. Landry A, Docherty P, Ouellette $S$, et al.: Causes and outcomes of markedly elevated C-reactive protein levels Recherche Les causes et les conséquences d' un niveau élevé de la protéine C réactive. Can. Fam. Physician. 2017; 63: 316-323.

11. Wu J, Jin $\mathrm{Y}, \mathrm{Li} \mathrm{H}$, et al.: Evaluation and significance of $\mathrm{C}$-reactive protein in the clinical diagnosis of severe pneumonia. Exp. Ther. Med. 2015; 10(1): 175-180. PubMed Abstract | Publisher Full Text | Free Full Text

12. Rizzello V, Liuzzo G, Di Giannuario G, et al.: 1059G/C polymorphism within the exon 2 of the C-reactive protein gene: Relationship to C-reactive protein levels and prognosis in unstable angina. Coron. Artery Dis. 2007; 18(7): 533-538. PubMed Abstract |Publisher Full Text

13. Syukriani YF: Polimorfisme genetik: teori migrasi dan patogenesis penyakit. UNPAD Press; 2019; 215.

14. Eklund C, Lehtimäki T, Hurme M: Epistatic effect of C-reactive protein (CRP) single nucleotide polymorphism (SNP) +1059 and interleukin-1B SNP +3954 on CRP concentration in healthy male blood donors. Int. J. Immunogenet. 2005 Aug; 32(4): 229-232.

Publisher Full Text

15. Wang W, Xu Y, Gao R, et al.: Detection of SARS-CoV-2 in Different Types of Clinical Specimens. JAMA. 2020; 323(18): 1843-1844.

16. Tan BYQ, Chew NWS, Lee GKH, et al.: Psychological Impact of the COVID-19 Pandemic on Health Care Workers in Singapore. Ann. Intern. Med. 2020; 173(4): 317-320. PubMed Abstract | Publisher Full Text | Free Full Text

17. Xiaomin L, Wei Z, Xiaojie $Y$, et al.: Prognostic value of C-reactive protein in patients with COVID-19 Xiaomin.J. Gerontol. Ser. A Biol. Med. Sci. 2018; 0813(April): 1-11.

18. Zulmansyah GIN, Agustian D, et al.: Underlying Data data for 'May mutation of SNP rs1800947 affect length of stay outcome of COVID-19 suspects?'. 2021.

Publisher Full Text 
The benefits of publishing with F1000Research:

- Your article is published within days, with no editorial bias

- You can publish traditional articles, null/negative results, case reports, data notes and more

- The peer review process is transparent and collaborative

- Your article is indexed in PubMed after passing peer review

- Dedicated customer support at every stage

For pre-submission enquiries, contact research@f1000.com 